\title{
Continental vs. Global Niche-Based Modelling of Freshwater Species' Distributions: How Big Are the Differences in the Estimated Climate Change Effects?
}

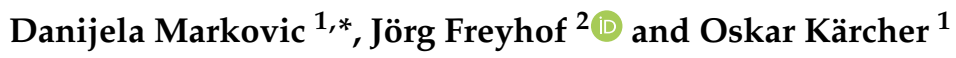 \\ 1 Faculty of Business Management and Social Sciences, Osnabrück University of Applied Sciences, \\ Caprivistr. 30A, 49076 Osnabrück, Germany; o.kaercher@hs-osnabrueck.de \\ 2 Museum für Naturkunde, Leibniz Institute for Evolution and Biodiversity Science, Invalidenstraße 43, \\ 10115 Berlin, Germany; joerg.freyhof@mfn.berlin \\ * Correspondence: markovic@quant-works.de; Tel.: +49-541-969-2033
}

check for updates

Citation: Markovic, D.; Freyhof, J.; Kärcher, O. Continental vs. Global Niche-Based Modelling of Freshwater Species' Distributions: How Big Are the Differences in the Estimated Climate Change Effects? Water 2021, 13, 816. https://doi.org/10.3390/ w13060816

Academic Editors: Valeria Lencioni and Dean Jacobsen

Received: 24 February 2021

Accepted: 14 March 2021

Published: 16 March 2021

Publisher's Note: MDPI stays neutral with regard to jurisdictional claims in published maps and institutional affiliations.

Copyright: (c) 2021 by the authors. Licensee MDPI, Basel, Switzerland. This article is an open access article distributed under the terms and conditions of the Creative Commons Attribution (CC BY) license (https:/ / creativecommons.org/licenses/by/ $4.0 /)$.

\begin{abstract}
Thermal response curves that depict the probability of occurrence along a thermal gradient are used to derive various species' thermal properties and abilities to cope with warming. However, different thermal responses can be expected for different portions of a species range. We focus on differences in thermal response curves (TRCs) and thermal niche requirements for four freshwater fishes (Coregonus sardinella, Pungitius pungitius, Rutilus rutilus, Salvelinus alpinus) native to Europe at (1) the global and (2) European continental scale. European ranges captured only a portion of the global thermal range with major differences in the minimum $\left(\mathrm{T}_{\min }\right)$, maximum $\left(\mathrm{T}_{\max }\right)$ and average temperature $\left(\mathrm{T}_{\mathrm{av}}\right)$ of the respective distributions. Further investigations of the model-derived preferred temperature $\left(\mathrm{T}_{\text {pref }}\right)$, warming tolerance $\left(\mathrm{WT}=\mathrm{T}_{\max }-\mathrm{T}_{\text {pref }}\right)$, safety margin $\left(\mathrm{SM}=\mathrm{T}_{\text {pref }}-\mathrm{T}_{\mathrm{av}}\right)$ and the future climatic impact showed substantially differing results. All considered thermal properties either were under- or overestimated at the European level. Our results highlight that, although continental analyses have an impressive spatial extent, they might deliver misleading estimates of species thermal niches and future climate change impacts, if they do not cover the full species ranges. Studies and management actions should therefore favor whole global range distribution data for analyzing species responses to environmental gradients.
\end{abstract}

Keywords: freshwater; preferred temperature; climate change; safety margin; thermal response curves; warming tolerance

\section{Introduction}

Predicting consequences of climate change across freshwater environments is central to fundamental and applied research in hydrology and ecology. Moreover, accurate predictions of species range shifts are critical to the development of management strategies to mitigate and adapt to climate change. The majority of research addressing the effect of climate change on species has focused on changes in species distributions derived using correlative niche-based species distribution models (SDMs) [1]. Application of SDMs in the context of predicting future species distributions is based on the assumption that a species will track the spatial position of its current environmental niche (see [1]). Specifically, the SDMs relate the observed environmental conditions (e.g., thermal conditions) to observed species distributions, and project the derived statistical relationships into the future using predictions of various climate change models. The methodological aspects of SDMs have been extensively studied, e.g., [1-3], exposing various sources of uncertainty. One of the factors that has been shown to strongly influence the estimation of the current species' thermal niche, i.e., the thermal response curve (TRC), is the restriction of the environmental range of data used to calibrate the SDMs [1-4]. Specifically, restricting the range of environmental conditions over which the SDMs are calibrated affects most the estimates 
of the upper and lower ends of TRCs [3], and thus the estimates of the species' thermal niche requirements such as the maximum/minimum temperature of occurrence or thermal range (defined as the difference between the maximum and minimum temperature of occurrence). Consequently, the range of the considered temperature conditions in SDMs plays a fundamental role for estimating a species' response along the thermal gradient and determining the future climatic suitability of current species' ranges [2-4].

The distribution of a species along a thermal gradient is commonly approximated by a unimodal, left or right skewed TRC, with a characteristic single optimum near the temperature where a species is most likely to be found [1,2]. Many studies have analyzed TRCs in order to describe current and predict future species distributions according to climate change scenarios [2-8]. Such assessments are often considered in order to quantify the effect of temperature on species distributions $[9,10]$, or to identify stenothermic or eurythermic species by classifying whether they have narrow or broad thermal responses $[6,11]$. However, most studies consider only portions of the whole species range for deriving species-specific thermal characteristics via SDMs, although responses may vary greatly with the geographical extent of the data (see [3,4]). Specifically, recent scientific literature is full of publications involving single country or continental data that are used to draw conclusions on the potential future species distributions, e.g., [4-11], without questioning such an approach given the impressive spatial data extent. Notwithstanding, we argue that despite impressive spatial extent, even the continental scale analyses might not be sufficient to estimate the potential climate change effects on species' distributions, if they do not cover the full observed species ranges.

The aim of this study is to quantify the extent of differences between the estimated species' thermal niche requirements and future climatic impacts arising from the use of continental (European native species range) instead of global species' range data (whole species range). Specifically, using niche-based species distribution models, we analyzed distributions of four freshwater fish species native to Europe (Coregonus sardinella, Pungitius pungitius, Rutilus rutilus and Salvelinus alpinus) and quantified differences between global and European range data in (i) thermal response curves, (ii) the associated thermal niche requirements, and (iii) future climatic impacts. Species selection was based on our previously published study where thermal response curves for 577 freshwater species from different taxonomic groups were investigated at the global scale (see [2]). In particular, among 473 fish species investigated in [2], for 52 fish substantial differences between TRCs at the global and the European continental scale were detected within our preliminary study. The four species discussed here (C. sardinella, P. pungitius, R. rutilus and S. alpinus) represent those with the most prominent thermal differences at the global and the European continental scale.

\section{Materials and Methods}

\subsection{Species Data}

Global distribution data of studied fish species native to Europe were derived from the IUCN Global Species Programme containing the known range of each species as presence and absence data in polygon shape files corresponding to global watershed boundaries [12,13] (see iucn.org/theme/species/our-work/iucn-red-list-threatened-species for more details; Esri maps of species' global ranges are provided at iucnredlist.org/, accessed on 18 April 2018). As mentioned in the introduction, among 473 fish species investigated in our previously published work (see [2]), the four species analyzed here (C. sardinella, P. pungitius, R. rutilus and S. alpinus) represent those fish with the most prominent differences in the thermal niche requirements at the global and the European continental scale (we remark that for 52 fish species substantial differences between the global and the European TRCs were detected and the corresponding results are provided in Supplementary Data). Coregonus sardinella belong to the family Coregonidae and S. alpinus belong to the family of Salmonidae and both have a common length of $20-25 \mathrm{~cm}$ and $40 \mathrm{~cm}$, respectively. Pungitius pungitius belongs to the family of Gasterosteidae and has a common length of 
5-7 cm, while $R$. rutilus belongs to the family of Leuciscidae and has a common length of $15-30 \mathrm{~cm}$.

At the global scale (Supplementary Table S1), species data were mapped to 228,064 HydroBasins level 8 catchments [14]. Occurrence numbers at the global scale ranged from 17,055 (S. alpinus) to 33,756 (R. rutilus) (Supplementary Table S2). European distribution data was defined as a subset of the global distribution data; overall covering 18,767 catchments (Supplementary Table S1). Occurrence numbers at the European scale ranged from 745 (C. sardinella) to 15,478 (R. rutilus).

\subsection{Climate Data}

Global climatic data were ascertained for the second half of the 20th century (1960-1990, "baseline") from the WorldClim (version 1.4) 30 arc-second dataset [15] (worldclim.org, accessed on 19 March 2018). Due to a lack of water temperature data given the global spatial extent of our study (228,064 catchments) and the fundamental shortcomings of using global relationships model to transform air temperatures to water temperature (see [2]), the focus of the results and the following discussion will be on the catchmentspecific mean annual air temperature (Tmeanair).

Future climate projections for Europe (18,767 catchments) were gathered for the middle of the 21st century ("2050s") from the CIAT (International Center for Tropical Agriculture) 30 arc-seconds gridded dataset (ccafs-climate.org, accessed on 19 March 2018). We focused on three climate models (MOHC-UK Met Office, Hadley Center, IPSL-Institut PierreSimon-Laplace and MPI-Max Planck Institute for Meteorology), each considering the RCP4.5 (Representative Concentration Pathways) emission scenario. RCP4.5 follows a medium-low mitigation of greenhouse gas emission and represents intermediate scenarios [16]. The gridded layers of the 20th and 21st century Tmeanair were mapped to HydroBasins level 8 resolution catchments using the ESRI ArcGIS zonal statistics tool for calculating the mean value for a polygon.

\subsection{Statistical Model}

Global and European distributions of the four fish species were modelled using Generalized Additive Models (GAMs; R package "gam"; see [17]), run in R language version 3.3.1 [18]. GAM is a non-parametric extension of generalized linear methods, and is widely used for modelling current and future distribution patterns of fish species. Moreover, compared to other methods used to parameterize species' thermal response curves, GAMs have greater flexibility regarding the response shape and have well performance at high collinearity (cf. [2]). Here, we applied smoothing by spline functions with three degrees of freedom. The probability of species occurrence along the thermal gradient represents the thermal response curve (TRC). Since our focus was on the species' thermal properties, the evaluation of the species' TRC was based on a univariate modelling approach, i.e., Tmeanair was the only explanatory variable.

Model performance was evaluated by calculating two performance measures: the area under the receiver operating characteristic (ROC) curve, AUC [19-21], and the true skill statistic (TSS = specificity + sensitivity -1 ), whereas specificity and sensitivity were the result of a probability threshold determination [22]. Here, the threshold for separating presences and absences of a species was determined by minimizing the absolute difference between specificity and sensitivity [23,24]. Accuracy of the performance measures was validated by splitting the data into a training $(80 \%)$ and validation $(20 \%)$ dataset 100 times. The average AUC and TSS values of the validations were used for the assessment of the predictive performance [25]. For the depiction of the uncertainty, we computed $95 \%$ confidence intervals (CIs) around the modelled probabilities of occurrence for each observation [26]. 


\subsection{Assessment of Thermal Properties}

Comparisons of TRCs between the global and European scale included analyses of: (1) Thermal range, defined as the difference between the maximum $\left(T_{\max }\right)$ and minimum temperature $\left(\mathrm{T}_{\mathrm{min}}\right)$ of occurrence; (2) Preferred temperature $\left(\mathrm{T}_{\text {pref }}\right)$, determined if the thermal response was unimodal, i.e., if a temperature that maximizes the probability of occurrence was uniquely determinable; (3) 'Warming tolerance' (WT), calculated as the difference between $\mathrm{T}_{\max }$ and $\mathrm{T}_{\text {pref }}\left(\mathrm{WT}=\mathrm{T}_{\max }-\mathrm{T}_{\text {pref }}\right.$ ); (4) 'Safety margin' (SM), calculated as the difference between $\mathrm{T}_{\text {pref }}$ and the average temperature across the species' distribution range $\left(\mathrm{T}_{\mathrm{av}}\right)\left(\mathrm{SM}=\mathrm{T}_{\text {pref }}-\mathrm{T}_{\mathrm{av}}\right)$; (5) Exposure to future global warming across the species' range, assessed by calculating the difference between the average of the projected temperatures of the three climate models and the species specific $\mathrm{T}_{\max }$. We note that safety margin (SM) and warming tolerance (WT) are the common terms used to describe the species thermal performance curves (TPCs) (see [27,28]). Here, we used the latter terms to provide comparable descriptors of the TRCs, but underline that the interpretation of SM and WT in the context of TRCs and TPCs is different. Specifically, while TPCs address the question of the species' performance within a certain thermal range, the TRCs address the question of the likelihood of species occurrence.

\section{Results and Discussion}

The validation mean AUC and TSS values with $0.82 \leq$ AUC $\leq 0.99$ and $0.47 \leq$ TSS $\leq 0.92$ were moderate to high for both the global and European scale (Supplementary Table S3). We note here that the overall accuracy of the calibrated models should be viewed in the context of the given data quality and the used modelling technique (see [29]). The uncertainty of the modelled occurrence probabilities was low for global scale models; however, uncertainty increased to the lower edges of the thermal gradient. Similarly, reducing the range of environmental data used to calibrate the models was found to cause unpredictable effects on the tails of the species response curves [3]. Furthermore, the variation in the geographical extent for parameterizing thermal response curves was manifested in shifts and significant shape differences of the curves. For C. sardinella, P. pungitius and R. rutilus at both scales a unimodal thermal response curve was present, whereas the global response curves were characterized by a shift towards lower temperatures (Figure 1). The European response curve of S. alpinus suggests a monotonic decreaser (i.e., the occurrence probability decreases with temperature increase), while the global thermal response curve was unimodal. The latter is not surprising as S. alpinus is known to have a circumpolar distribution with the northernmost extant of all freshwater fishes, thus having little opportunities to move northward in response to climate warming [30].

The quantification of different thermal properties of the species at both scales such as the thermal range, the preferred temperature, warming tolerance and safety margin reflected varying implications for the respective species. In particular, comparisons with globally derived thermal properties showed that each of the named property dimensions was either more optimistic or pessimistic when quantified with native range data [31]. Global thermal ranges for each of the four species were greater than European thermal ranges (see also [32]). Differences between the thermal ranges inferred from the global and European extents ranged from $6.5^{\circ} \mathrm{C}$ (S. alpinus) to $20.1^{\circ} \mathrm{C}$ (P. pungitius) (Table 1). For all species, global minimum temperature $\left(\mathrm{T}_{\min }\right)$ was significantly lower than European $\mathrm{T}_{\text {min }}$ and global maximum temperature $\left(\mathrm{T}_{\max }\right)$ exceeded European $\mathrm{T}_{\max }$ for all species, except for S. alpinus (Table 1). 


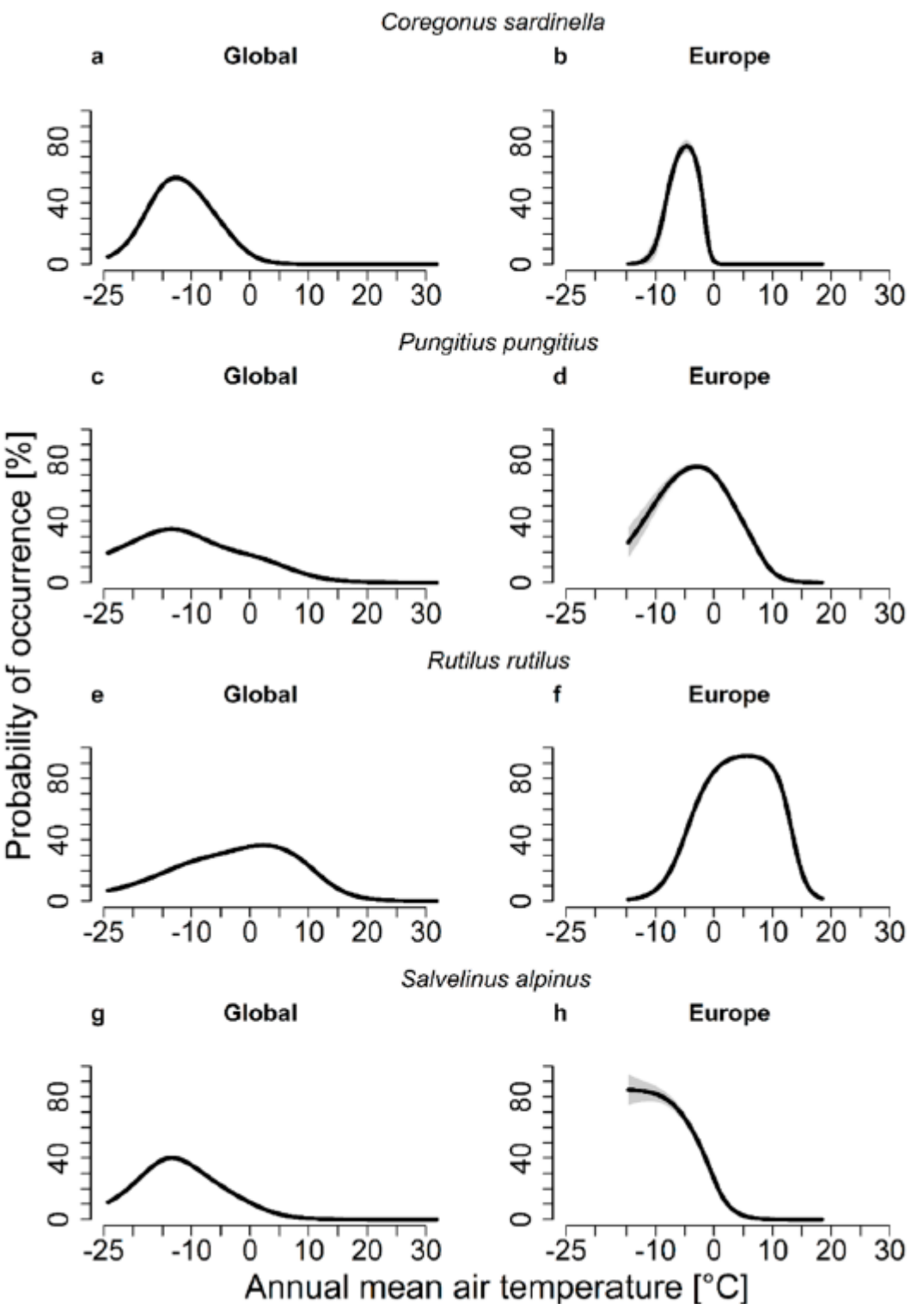

Figure 1. Thermal response curves along the annual mean air temperature gradient. Thermal response curves are displayed for $(\mathbf{a}, \mathbf{b})$ C. sardinella, $(\mathbf{c}, \mathbf{d})$ P. pungitius, $(\mathbf{e}, \mathbf{f})$ R. rutilus, and $(\mathbf{g}, \mathbf{h})$ S. alpinus at the global and European scale, respectively. The grey area around the response curves represents the $95 \%$ confidence interval.

Table 1. Comparison between the thermal characteristics inferred from global and European species distributions.

\begin{tabular}{|c|c|c|c|c|c|}
\hline \multirow{2}{*}{ Scheme } & \multirow{2}{*}{$\begin{array}{l}\text { Annual Mean Air Temperature } \\
\left({ }^{\circ} \mathrm{C}\right)\end{array}$} & \multicolumn{4}{|c|}{ Species } \\
\hline & & Coregonus sardinella & Pungitius pungitius & Rutilus rutilus & Salvelinus alpinus \\
\hline Global & $\begin{array}{c}\mathrm{T}_{\min } \\
\mathrm{T}_{\max } \\
\text { Thermal Range } \\
\mathrm{T}_{\mathrm{av}} \\
\text { Median } \\
\text { St. Deviation }\end{array}$ & $\begin{array}{c}-21.2 \\
2.9 \\
24.1 \\
-9.3 \\
-10.0 \\
4.8\end{array}$ & $\begin{array}{l}-21.5 \\
17.4 \\
38.9 \\
-5.0 \\
-5.7 \\
7.9\end{array}$ & $\begin{array}{c}-19.9 \\
17.9 \\
37.8 \\
0.5 \\
1.3 \\
7.7\end{array}$ & $\begin{array}{c}-20.6 \\
7.5 \\
28.1 \\
-8.0 \\
-9.2 \\
6.1\end{array}$ \\
\hline European & $\begin{array}{c}\mathrm{T}_{\min } \\
\mathrm{T}_{\max } \\
\text { Thermal Range } \\
\mathrm{T}_{\mathrm{av}} \\
\text { Median } \\
\text { St. Deviation }\end{array}$ & $\begin{array}{c}-8.9 \\
-0.6 \\
8.3 \\
-3.5 \\
-2.8 \\
2.1\end{array}$ & $\begin{array}{c}-8.9 \\
9.9 \\
18.8 \\
2.3 \\
2.1 \\
3.6\end{array}$ & $\begin{array}{l}-8.0 \\
15.9 \\
23.9 \\
5.4 \\
5.5 \\
4.0\end{array}$ & $\begin{array}{l}-14.1 \\
7.5 \\
21.6 \\
-1.1 \\
-0.6 \\
3.6\end{array}$ \\
\hline
\end{tabular}


Preferred temperatures $\left(\mathrm{T}_{\text {pref }}\right)$ at both spatial scales could be determined for $C$. sardinella, P. pungitius and R. rutilus because of unimodal thermal response curves where a temperature that maximizes the probability of occurrence is uniquely determinable (Table 2). $\mathrm{T}_{\text {pref }}$ inferred from the global scale analyses was $3.5-10.5^{\circ} \mathrm{C}$ lower than the preferred temperature determined at the European level for C. sardinella, P. pungitius and R. rutilus. In particular, $\mathrm{T}_{\text {pref }}$ for $C$. sardinella and P. pungitius inferred from the global analysis was more than $8^{\circ} \mathrm{C}$ lower than European $\mathrm{T}_{\text {pref. }}$. For R. rutilus the difference was smaller with $\mathrm{T}_{\text {pref }}=2.2^{\circ} \mathrm{C}$ and $\mathrm{T}_{\text {pref }}=5.7^{\circ} \mathrm{C}$ at the global and European scale, respectively. Global $\mathrm{T}_{\text {pref }}=-13.4^{\circ} \mathrm{C}$ of S. alpinus was in the range of European $\mathrm{T}_{\min }=-14.1^{\circ} \mathrm{C}$. Due to the non-unimodal European TRC of $S$. alpinus, $\mathrm{T}_{\text {pref }}$ could not be determined for this species. Overall, our results regarding S. alpinus substantially extent those reported in [30], as these were based on known ranges of this species across Sweden only.

Table 2. Different thermal properties of the analyzed species for the two considered spatial extents.

\begin{tabular}{|c|c|c|c|c|c|}
\hline \multirow{2}{*}{ Scale } & \multirow{2}{*}{$\underset{\left({ }^{\circ} \mathrm{C}\right)}{\text { Annual Mean }}$} & \multicolumn{4}{|c|}{ Species } \\
\hline & & Coregonus sardinella & Pungitius pungitius & Rutilus rutilus & Salvelinus alpinus \\
\hline Global & $\begin{array}{l}\mathrm{T}_{\text {pref }} \\
W T \\
\mathrm{WM}\end{array}$ & $\begin{array}{c}-12.7 \\
15.6 \\
-3.4\end{array}$ & $\begin{array}{c}-13.4 \\
30.8 \\
-8.4\end{array}$ & $\begin{array}{c}2.2 \\
15.7 \\
1.7\end{array}$ & $\begin{array}{c}-13.4 \\
20.9 \\
-5.4\end{array}$ \\
\hline European & $\begin{array}{l}\mathrm{T}_{\text {pref }} \\
\mathrm{WT} \\
\mathrm{SM}\end{array}$ & $\begin{array}{c}-4.7 \\
4.1 \\
-1.2\end{array}$ & $\begin{array}{l}-2.9 \\
12.8 \\
-5.2\end{array}$ & $\begin{array}{c}5.7 \\
10.2 \\
0.3\end{array}$ & $\begin{array}{l}\text { NA } \\
\text { NA } \\
\text { NA }\end{array}$ \\
\hline
\end{tabular}

Warming tolerances $\left(\mathrm{WT}=\mathrm{T}_{\max }-\mathrm{T}_{\text {pref }}\right.$ ) of $C$. sardinella and P. pungitius deduced from the global analysis were more than $11{ }^{\circ} \mathrm{C}$ greater than the WTs obtained by the European analysis (see also [33]) (Table 2). The latter suggests a mismatch between the environmental conditions across the European and the global ranges of these species, and highlights the importance of capturing the whole environmental niche by the models. For R. rutilus a difference of $5.5^{\circ} \mathrm{C}$ was observed, where a greater WT was determined at the global scale. S. alpinus had a global WT that approximately corresponded to the European thermal range (global $\mathrm{WT}=20.9{ }^{\circ} \mathrm{C}$ and European thermal range $=21.6{ }^{\circ} \mathrm{C}$ ). European $\mathrm{WT}$ for S. alpinus could not be determined, because of the absence of a uniquely determinable $\mathrm{T}_{\text {pref }}$. Additional comparisons of catchment-specific global and European WTs are provided in the Supplementary Information (Supplementary Figures S1-S4).

For C. sardinella and P. pungitius the global safety margin was $2-3{ }^{\circ} \mathrm{C}$ lower than at the European scale (Table 2), i.e., the exceeding of the preferred temperature $\left(\mathrm{T}_{\text {pref }}\right)$ by the current average habitat temperature $\left(\mathrm{T}_{\mathrm{av}}\right)$ was underestimated with European data. For R. rutilus the European SM was $1.4{ }^{\circ} \mathrm{C}$ lower than the global SM. European SM for $S$. alpinus could not be determined, however, the species had a negative global SM. Further catchment-specific comparisons are provided in the Supplementary Information (Supplementary Figures S5-S8).

Differences between the average future projection for each catchment and speciesspecific $\mathrm{T}_{\max }$ outlined that European analyses convey a more pessimistic view of the future climatic impact as $T_{\max }$ of the global range was higher than $T_{\max }$ of the European range for all species, except for S. alpinus (see also [3]) (Table 1, Supplementary Figure S12). Greater differences of the future climatic impact assessment between the global and European scale were observable for C. sardinella (Supplementary Figure S9) and P. pungitius (Supplementary Figure S10). For R. rutilus (Supplementary Figure S11), both scales indicated mainly future temperatures below $T_{\max }$, with few exceptions for catchments in the southern ranges of the respective species distribution at the European analysis scale. This result is in agreement with [34], who predicted range expansion for R. rutilus under climate change. However, in view of our results, the outcomes of the latter study need to be considered with caution, as the data used to calibrate the models were limited to Great Britain only. Furthermore, we note that the observed maximum temperature of occurrence $\left(\mathrm{T}_{\max }\right)$ derived from global 
range data might be inaccurate ("due to the absence of hotter areas under current global climate" [35]), and thus allowing the species to persist in temperatures exceeding $\mathrm{T}_{\max }$.

\section{Conclusions}

Focusing only on native portions of species ranges and not on the whole range can result in substantially different thermal response curves (TRCs) and species' thermal properties, thus leading to deceptive conclusions for management strategies. Among the four analyzed species the TRCs at the European and global scale varied greatly. All species indicated broader thermal ranges at the global level, while shifts of the TRCs towards colder temperatures were not captured by the European dataset for three out of four species. Thus, European response analyses may create pessimistic views of allegedly specialists with small thermal ranges. Furthermore, species' thermal niche requirements deduced from the European analyses either were under- or overestimated. Similarly, regions where a species is likely to suffer from future climatic impacts can be different for global and European scale analyses, unless the European scale already includes the whole known species distribution range (see also [31,32,36]).

Factors such as new distribution possibilities [37], biotic interactions, future anthropogenic responses to environmental change and thermal adaptations [38] may enable species to cope with environments in regions outside their native distribution range [31,33]. However, although local adaptation along thermal gradients is possible, the increased fitness in warmer environments does not transfer to the next generation [39], and is therefore subject to considerable uncertainty in the context of projecting future species distributions. In summary, our findings highlight that, although continental analyses have an impressive spatial extent, they might deliver misleading estimates of climate change effects on species' distributions. Consequently, management actions should thus rely on models that consider the whole known species distribution ranges. In particular, we argue that future studies must carefully justify the usage of continental data (or country-based data) when global data is available.

Supplementary Materials: The following are available online at https:/ / www.mdpi.com/2073-444 $1 / 13 / 6 / 816 / s 1$, supplementary tables and figures (Supplementary Information.pdf) and supplementary data (Supplementary Data.xlsx).

Author Contributions: Conceptualization, D.M. and O.K.; methodology, D.M. and O.K.; software, D.M. and O.K.; validation, D.M., O.K. and J.F.; formal analysis, D.M. and O.K.; investigation, O.K.; resources, D.M.; data curation, J.F. and D.M.; writing—original draft preparation, D.M. and O.K. writing - review and editing, all authors.; visualization, O.K.; project administration, D.M.; funding acquisition, D.M. All authors have read and agreed to the published version of the manuscript.

Funding: This research was funded by DFG under Grant MA 6593/2-1.

Data Availability Statement: Data on European freshwater species were collected during the EU-funded research project BioFresh and are available at https:/ /www.iucnredlist.org/technicaldocuments/spatial-data. More information is available at https:/ / project.freshwaterbiodiversity.eu/. Gridded climate data for the second half of the 20th century were extracted from the WorldClim data set and are available at www.worldclim.org. Data on future climate projections were gathered from the CIAT (International Center for Tropical Agriculture) dataset available at www.ccafs-climate.org.

Conflicts of Interest: The authors declare no conflict of interest. The funders had no role in the design of the study; in the collection, analyses, or interpretation of data; in the writing of the manuscript, or in the decision to publish the results.

\section{References}

1. Franklin, J. Mapping Species Distributions: Spatial Inference and Prediction; Cambridge University Press: Cambridge, UK, 2009.

2. Kärcher, O.; Hering, D.; Frank, K.; Markovic, D. Freshwater species distributions along thermal gradients. Ecol. Evol. 2019, 9, 111-124. [CrossRef] [PubMed]

3. Thuiller, W.; Brotons, L.; Araújo, M.B.; Lavorel, S. Effects of restricting environmental range of data to project current and future species distributions. Ecography 2004, 27, 165-172. [CrossRef] 
4. Filipe, A.F.; Markovic, D.; Pletterbauer, F.; Tisseuil, C.; De Wever, A.; Schmutz, S.; Bonada, N.; Freyhof, J. Forecasting fish distribution along stream networks: Brown trout (Salmo trutta) in Europe. Divers. Distrib. 2013, 19, 1059-1071. [CrossRef]

5. Lassalle, G.; Béguer, M.; Beaulaton, L.; Rochard, E. Diadromous fish conservation plans need to consider global warming issues: An approach using biogeographical models. Biol. Conserv. 2008, 141, 1105-1118. [CrossRef]

6. Logez, M.; Bady, P.; Pont, D. Modelling the habitat requirement of riverine fish species at the European scale: Sensitivity to temperature and precipitation and associated uncertainty. Ecol. Freshw. Fish 2012, 21, 266-282. [CrossRef]

7. De Frenne, P.; Rodríguez-Sánchez, F.; Coomes, D.A.; Baeten, L.; Verstraeten, G.; Vellend, M.; Bernhardt-Römermann, M.; Brown, C.D.; Brunet, J.; Cornelis, J.; et al. Microclimate moderates plant responses to macroclimate warming. Proc. Natl. Acad. Sci. USA 2013, 110, 18561-18565. [CrossRef]

8. Markovic, D.; Carrizo, S.F.; Kärcher, O.; Walz, A.; David, J.N.W. Vulnerability of European freshwater to climate change. Glob. Chang. Biol. 2017, 23, 3567-3580. [CrossRef]

9. Carrascal, L.M.; Villén-Pérez, S.; Palomino, D. Preferred temperature and thermal breadth of birds wintering in peninsular Spain: The limited effect of temperature on species distribution. PeerJ 2016, 4, e2156. [CrossRef]

10. Isaak, D.J.; Wenger, S.J.; Young, M.K. Big biology meets microclimatology: Defining thermal niches of ectotherms at landscape scales for conservation planning. Ecol. Appl. 2017, 27, 977-990. [CrossRef]

11. Barnagaud, J.-Y.; Devictor, V.; Jiguet, F.; Barbet-Massin, M.; Le Viol, I.; Archaux, F. Relating Habitat and Climatic Niches in Birds. PLoS ONE 2012, 7, e32819. [CrossRef] [PubMed]

12. IUCN Red List of Threatened Species; Version 2013.2; IUCN: Gland, Switzerland, 2013.

13. Guidelines for Using the IUCN Red List Categories and Criteria; Version 11; Standards and Petitions Subcommittee: Gland, Switzerland, 2014.

14. Lehner, B.; Grill, G. Global river hydrography and network routing: Baseline data and new approaches to study the world's large river systems. Hydrol. Process. 2013, 27, 2171-2186. [CrossRef]

15. Hijmans, R.J.; Cameron, S.E.; Parra, J.L.; Jones, P.G.; Jarvis, A. Very high resolution interpolated climate surfaces for global land areas. Int. J. Clim. 2005, 25, 1965-1978. [CrossRef]

16. van Vuuren, D.P.; Edmonds, J.; Kainuma, M.; Riahi, K.; Thomson, A.; Hibbard, K.; Hurtt, G.C.; Kram, T.; Krey, V.; Lamarque, J.-F.; et al. The representative concentration pathways: An overview. Clim. Chang. 2011, 109, 5-31. [CrossRef]

17. Hastie, T. GAM: Generalized Additive Models R Package; Version 1.14; GAM: Zurich, Switzerland, 2016.

18. R Development Core Team. R: A Language and Environment for Statistical Computing; R Foundation for Statistical Computing: Vienna, Austria, 2018.

19. Swets, J.A. Measures of accuracy of diagnostic systems. Science 1988, 240, 1285-1293. [CrossRef]

20. Hosmer, D.W.; Lemeshow, S. Applied Logistic Regression; Wiley: New York, NY, USA, 2000.

21. Manel, S.; Williams, H.C.; Ormerod, S.J. Evaluating presence-absence models in ecology: The need to account for prevalence. J. Appl. Ecol. 2001, 38, 921-931. [CrossRef]

22. Allouche, O.; Tsoar, A.; Kadmon, R. Assessing the accuracy of species distribution models: Prevalence, kappa and the true skill statistic (TSS). J. Appl. Ecol. 2006, 43, 1223-1232. [CrossRef]

23. Fielding, A.H.; Bell, J.F. A review of methods for the assessment of prediction errors in conservation presence/absence models. Environ. Conserv. 1997, 24, 38-49. [CrossRef]

24. Jiménez-Valverde, A.; Lobo, J.M. Threshold criteria for conversion of probability of species presence to either-or presence-absence. Acta Oecologica 2007, 31, 361-369. [CrossRef]

25. Dormann, C.F.; Purschke, O.; Márquez, J.R.G.; Lautenbach, S.; Schröder, B. Components of uncertainty in species distribution analysis: A case study of the great grey shrike. Ecology 2008, 89, 3371-3386. [CrossRef]

26. De Jong, P.; Heller, G.Z. Generalized Linear Models for Insurance Data; Cambridge University Press (CUP): Cambridge, UK, 2008.

27. Deutsch, C.A.; Tewksbury, J.J.; Huey, R.B.; Sheldon, K.S.; Ghalambor, C.K.; Haak, D.C.; Martin, P.R. Impacts of climate warming on terrestrial ectotherms across latitude. Proc. Natl. Acad. Sci. USA 2008, 105, 6668-6672. [CrossRef] [PubMed]

28. Comte, L.; Olden, J.D. Climatic vulnerability of the world's freshwater and marine fishes. Nat. Clim. Chang. 2017, 7, 718-722 [CrossRef]

29. Huang, J.; Frimpong, E.A. Using Historical Atlas Data to Develop High-Resolution Distribution Models of Freshwater Fishes. PLoS ONE 2015, 10, e0129995. [CrossRef] [PubMed]

30. Hein, C.L.; Öhlund, G.; Englund, G. Future Distribution of Arctic Char Salvelinus alpinus in Sweden under Climate Change: Effects of Temperature, Lake Size and Species Interactions. Ambio 2012, 41, 303-312. [CrossRef]

31. Bush, A.; Catullo, R.A.; Mokany, K.; Thornhill, A.H.; Miller, J.T.; Ferrier, S. Truncation of thermal tolerance niches among Australian plants. Glob. Ecol. Biogeogr. 2018, 27, 22-31. [CrossRef]

32. Lee-Yaw, J.A.; Kharouba, H.M.; Bontrager, M.; Mahony, C.; Csergő, A.M.; Noreen, A.M.; Colin, M.; Schuster, R.; Angert, A.L. A synthesis of transplant experiments and ecological niche models suggests that range limits are often niche limits. Ecol. Lett. 2016, 19, 710-722. [CrossRef] [PubMed]

33. Vetaas, O.R. Realized and potential climate niches: A comparison of four Rhododendron tree species. J. Biogeogr. 2002, 29, 545-554. [CrossRef]

34. Ruiz-Navarro, A.; Gillingham, P.K.; Britton, J.R. Shifts in the climate space of temperate cyprinid fishes due to climate change are coupled with altered body sizes and growth rates. Glob. Chang. Biol. 2016, 22, 3221-3232. [CrossRef] [PubMed] 
35. Feeley, K.J.; Silman, M.R. Biotic attrition from tropical forests correcting for truncated temperature niches. Glob. Chang. Biol. 2010, 16, 1830-1836. [CrossRef]

36. Fitzpatrick, M.C.; Hargrove, W.W. The projection of species distribution models and the problem of non-analog climate. Biodivers. Conserv. 2009, 18, 2255-2261. [CrossRef]

37. Kletou, D.; Hall-Spencer, J.M.; Kleitou, P. A lionfish (Pterois miles) invasion has begun in the Mediterranean Sea. Mar. Biodivers. Rec. 2016, 9, 305. [CrossRef]

38. Angilletta, M.J. Thermal Adaptation: A Theoretical and Empirical Synthesis; Oxford University Press: Oxford, UK, 2009.

39. Jutfelt, F. Metabolic adaptation to warm water in fish. Funct. Ecol. 2020, 34, 1138-1141. [CrossRef] 